\title{
Social determinants of mental health care systems: intensive community based Care in the Veterans Health Administration
}

\author{
Ish P. Bhalla ${ }^{1,2^{*}}$ (D), Elina A. Stefanovics ${ }^{1,3}$ and Robert A. Rosenheck ${ }^{1,3,4}$
}

\begin{abstract}
Background: Since deinstitutionalization in the 1950s-1970s, public mental health care has changed its focus from asylums to general hospitals, outpatient clinics and specialized community-based programs addressing both clinical and social determinants of mental health. Analysis of the place of community-based programs within a comprehensive health system such as the Veterans Health Administration (VHA) may illuminate the role of social forces in shaping contemporary public mental health systems.
\end{abstract}

Methods: National VHA administrative data were used to compare veterans who exclusively received outpatient clinic care to those receiving four types of specialized community-based services, addressing: 1) functional disabilities from severe mental illness (SMI), 2) justice system involvement, 3) homelessness, and 4) vocational rehabilitation. Bivariate comparisons and multinomial logistic regression analyses compared groups on demographics, diagnoses, service use, and psychiatric prescription fills.

Results: An hierarchical classification of 1,386,487 Veterans who received specialty mental health services from VHA in Fiscal Year 2012, showed 1,134,977 (81.8\%) were seen exclusively in outpatient clinics; 27,931 (2.0\%) received intensive SMI-related services; 42,985 (3.1\%) criminal justice services; 160,273 (11.6\%) specialized homelessness services; and 20,921 (1.5\%) vocational services. Compared to those seen only in clinics, veterans in the four community treatment groups were more likely to be black, diagnosed with HIV and hepatitis, had more numerous substance use diagnoses and made far more extensive use of mental health outpatient and inpatient care.

Conclusions: Almost one-fifth of VHA mental health patients receive community-based services prominently addressing major social determinants of health and multimorbid substance use disorders.

\section{Background}

Care for people with psychiatric disorders has undergone extraordinary changes in the past 70 years from a focus on asylum care to a "de facto" system of diverse, largely non-institutional services [1-3]. A distinctive feature is the provision of community-based often intensive

\footnotetext{
* Correspondence: ish.bhalla@yale.edu

'Yale University Department of Psychiatry, 950 Campbell Ave, Building 35, West Haven, CT 06516, USA

${ }^{2}$ University of California, Los Angeles National Clinician Scholars Program, 1100 Glendon Ave, Suite 900, Los Angeles, CA 90024, USA

Full list of author information is available at the end of the article
}

services for the most vulnerable, those long thought to be the most inadequately served [4]. In 1950, care for people with SMI, provided in over 500,000 state mental hospital beds [5], and was a target of public scorn [6]. By 1970, the majority of these beds had been closed and acute care was provided primarily in general hospitals, with longer term institutional care in nursing and board and care homes [7], and outpatient care in public clinics bolstered by newly developed antipsychotic and other psychiatric medications. By 1980, a substantial academic literature had developed decrying the failures of deinstitutionalization and the neglect of people with the

(c) The Author(s). 2020 Open Access This article is licensed under a Creative Commons Attribution 4.0 International License, which permits use, sharing, adaptation, distribution and reproduction in any medium or format, as long as you give appropriate credit to the original author(s) and the source, provide a link to the Creative Commons licence, and indicate if changes were made. The images or other third party material in this article are included in the article's Creative Commons licence, unless indicated otherwise in a credit line to the material. If material is not included in the article's Creative Commons licence and your intended use is not permitted by statutory regulation or exceeds the permitted use, you will need to obtain permission directly from the copyright holder. To view a copy of this licence, visit http://creativecommons.org/licenses/by/4.0/. The Creative Commons Public Domain Dedication waiver (http://creativecommons.org/publicdomain/zero/1.0/) applies to the data made available in this article, unless otherwise stated in a credit line to the data. 
greatest needs [8]. Researchers showed that Assertive Community Treatment (ACT) [9] and other forms of intensive community-based care could provide humane services in non-institutional settings [10] at little or no additional cost [11]. Here too, critics claimed programs were under-funded [12]. Specialized psychiatric rehabilitation services were also developed to restore community adaptation and productive functioning [13-15], but these services were also believed to be of limited availability $[16,17]$.

In the 1980s an unanticipated crisis of homelessness emerged. Initially viewed as a failure of deinstitutionalization because many homeless adults had SMI [18], it was eventually recognized to be more a consequence of the loss of affordable housing and the decline in public income support $[19,20]$ - a one-two punch that fell hard on people with SMI and addictions [21]. This highly visible subgroup of homeless adults was recognized to need income, housing and specialized community outreach services as well as psychiatric care.

In an apparent rebound of institutionalism, the criminal the justice system exploded, in large part due to harsh new drug laws, and became an unwanted new asylum for people with psychiatric disorders representing, to many, a de facto criminalization of mental illness [22-24]. In response, diversion programs were designed to create a channel from the criminal justice system to mental health services [25].

The current system of community-based care for people with SMI thus developed in response both biomedical innovations and what has increasingly been referred to as social determinants of mental health [26] (i.e. social determinants of mental illness) [27-29]. The result has been a non-institutional system composed of two broad components: a standard clinic-based component backed by a limited hospital capacity, that serves the majority of patients, providing medications and behavioral therapies; and a second, outwardly facing, community focused component providing more resource intensive services to patients most impacted by "social determinants" and in need of specialized in vivo care. These community-based services were initially conceptualized as replacing care previously provided by state hospitals, but, as suggested above, they also emerged in response to a broad array of social and economic developments.

The Veterans Health Administration (VHA) of the United States Department of Veterans Affairs (VA) is a nationally integrated health system with a specific mission to provide comprehensive healthcare to eligible veterans of military service, i.e. those discharged from active military duty under conditions other than dishonorable with special priorities for those with service-related disabilities, possible post-traumatic stress disorder, or exposed to military sexual trauma [30]. VA also offers income benefits to veterans who incurred adverse health effects during military service and other rehabilitative, educational and home mortgage benefits.

In many ways VHA mental health care has followed the same evolution as outlined above in other public mental health systems, with extensive bed closures, expansion of outpatient services, and use of the same biomedical innovations. VHA also responded to the same social phenomena with specialized community-based services although these services are only available to veterans formally enrolled in VHA, and in many cases such services may be more available in VHA that elsewhere in other US mental health systems [31]. The VHA is distinctive in that its electronic health records system comprehensively documents sociodemographic characteristics and clinical diagnoses as well as service use and prescribed medications of those it serves. VHA data thus offer a unique opportunity to empirically examine place of intensive community-based mental health services in a twenty-first century system of care and the distinctive characteristics of the veterans it cares for.

This study uses national VHA data on 1.3 million veterans who received specialized mental health services from VHA in FY 2012, 240,000 (18\%) of whom received often intensive community-based services that can be classified in four types: 1) ACT-like intensive case management and recovery-oriented day program services for veterans disabled by serious mental illness (SMI) [3234]; 2) outreach service to veterans involved in the criminal justice system [35-38]; 3) outreach and housing services for homeless veterans [39-43], and 4) rehabilitation and community-based employment services [44-46]. The primary goal of the criminal justice programs was outreach and linkage to standard VHA outpatient services. We included these programs in this study because of they represent a community-based service related to social problems as well as medical/psychiatric ones. In fact, historically, these programs were an outgrowth of the development of community-based programs for homeless veterans, many of whom have criminal justice problems. While these programs have been studied individually, no studies have taken a broad view of the development of community-based programs within the VHA mental health care system and examined the characteristics of veterans served by these programs together in a single analysis that examined their relative size and compared their participants to veterans served by standard outpatient clinics.

In this study veterans receiving these four specialized community-based services are compared to those who received only clinic-based services on socio-demographic and diagnostic characteristics and on patterns of mental health and medical service use. While a proportion of 
veterans were served by multiple programs, our primary intention was to describe how these programs can be understood together as a community-based response to diverse social determinants of health. We further compare the veterans they serve to those treated in standard outpatient mental health clinics. Intensive communitybased services for veterans, particularly case management services, were originally designed to provide psychiatric treatment to people with SMI. Our central observation is that the VHA responded to social determinants of veteran health in the community and designed programs to serve these veterans in vivo where their complex social issues arose. There have been many efforts in recent years to develop a comprehensive definition of social determinants of health $[47,48]$ and all have involved multiple, complex dimensions of functioning, general well-being, and social disadvantage. We take a less ambitious, more incrementalist approach to this issue examining the way a few, highly visible, social problems spurred the development of a new array of VHA programs. In this process VHA reached out to veterans with both distinctive social problems and complex mental health difficulties characterized by behavioral multimorbidities that could be addressed by one or another, or sometimes by more than one of these programs.

There has been particular interest in recent years in multi-morbidity, the co-occurrence of mutually exacerbating psychiatric, substance use and medical disorders which are responsible for severe functional impairments and place extensive demands on health care systems $[49,50]$. We sought to pay simultaneous attention to both key social determinants of health that impacted Veterans, and their clinical multimorbidity in an examination of factors that might illuminate the place of intensive community-based programs in contemporary mental health service delivery.

\section{Methods \\ Sample}

Using national VHA data from FY 2012, a total of 1,386, 487 veterans were identified who had used specialty mental health care. These veterans were classified into groups by the types of services they received. Community based services include those predominantly delivered outside the offices of the health care system to directly address social risks to health such as homelessness, incarceration, poor social functioning, poverty, and lack of employment skills. These services are not always provided outside of health system facilities, but they are all heavily focused on practical skills, supports for community living, and addressing individual social as well as medical circumstances. Since some veterans receive services from multiple programs, we classified them hierarchically, for analytic purposes, in mutually exclusive categories, including first, the most intensive longterm programs for SMI, followed by the two outreach programs addressing veterans involved in the criminal justice system and/or who were homeless, and then psychiatric rehabilitation programs, often provided as an ancillary to other clinical services. The remaining group was veterans seen only in office-based outpatient clinics. Thus while some veterans were treated in more than one community program $(21.3 \%$ of those seen in any community program), they were only included in one community treatment group in our analytic classification and most veterans seen in intensive community based programs $(62.2 \%)$ were also seen in clinic settings.

\section{Measures}

Measures, obtained from a pre-constructed dataset from the Northeast Program Evaluation Center, documented sociodemographic variables including age, sex, race, geographic residence (urban or rural), national region, income, VA pension status, service-connection disability status (VA income support programs), and homelessness in the past year (identified through use of specialized homeless services and the V60 ICD9 code). Geographic measures were obtained through zip codes using the Rural-Urban Commuting Area classification [51].

Medical diagnoses were selected based on those included in the Charlson comorbidity index, an aggregate measure of comorbidity that predicts 1-year mortality using a weighted sum of medical comorbidities [52]. In addition to the Charlson index itself, medical diagnoses known to be associated with mental illness and substance use were included, such as hepatic disease, human immunodeficiency virus infection (HIV) and pain diagnoses, using an array of codes described elsewhere [53].

Psychiatric diagnoses included schizophrenia, bipolar disorder, major depressive (ICD-9.

296.2-296.39) and other depressive disorders (ICD9300.4x, 296.9x, 301.10-301.19, 311.x), posttraumatic stress disorder (ICD-9309.81), anxiety disorders (ICD9300.xx excluding 300.4), and personality disorders (ICD-9301.9). In addition, 7 drug use disorders were included in the analysis: opiate (ICD-9304.0x or 305.5), cannabis (ICD-9304.3x or 305.2), cocaine (ICD-9304.2x or 305.6), barbiturates (ICD-9304.1x), amphetamines (ICD-9304.4x or 305.7), and hallucinogens (ICD-9304.5x or 305.3).

As a measure of multi-morbidity, summary variables were created as a count of the number of medical diagnoses, psychiatric diagnoses, and substance use diagnoses, and the total number of psychiatric and substance use diagnoses. 
VHA outpatient health service utilization was derived from clinic stop codes (specific codes are available upon request) representing general psychiatric care, substance use specialty care, primary care, emergency department visits, and each of the four types of community psychiatric care.

Psychotropic medication fills were classified as antipsychotics, antidepressants, anxiolytic/sedative/hypnotics, stimulants, anticonvulsants/mood stabilizers and lithium.

\section{Analysis}

Bivariate analyses were used to compare veterans treated only in mental health clinics to those who received services from each of the four hierarchically classified types of intensive community based services.

Because the subgroups examined in involve many tens of thousands of Veterans, small group differences with little clinical importance would likely be statistically significant. We thus relied on effect sizes to identify substantial differences between groups. Cohen's $d$ was calculated for continuous variables (the difference in means between groups divided by their pooled standard deviation); and risk ratios for dichotomous variables representing proportions. A cutoff value of $>0.20$ or $<-$ 0.20 was used as a threshold for at least a small difference in Cohen's $d$ [54] and risk ratios of $>1.5$ or $<0.67$ for dichotomous variables.

Multinomial logistic regression analysis was then used to identify the set of measures that independently differentiated veterans who had been treated in each of the four sub-specialty community health programs from those treated in mental health clinics only. Variables included in the multivariable analyses were those we had previously identified as being substantially different between the groups based effect size differences in bivariate comparisons.

All analyses were conducted using SAS statistical software (version 9.2; SAS Institute Inc., Cary, NC).

\section{Results}

Among the total of $1,386,487$ veterans who had received specialty mental health services, 252,110 (18.2\%) received specialized intensive community-based services. In our unduplicated hierarchical classification 27,931 (2.0\%) were classified in the intensive SMI services group; $42,985(3.1 \%)$ in the criminal justice outreach group; 160,273 (11.6\%) in homelessness services; and 20, $921(1.5 \%)$ in vocational services.

Bivariate analysis showed that veterans treated in criminal justice, homeless and vocational programs were substantially younger than those seen exclusively in outpatient mental health clinics. Veterans in the employment program group but not in the SMI program group had lower incomes (see comparisons using Cohen's d in the right hand columns of Table 1). Veterans seen in each of the four community-based programs were substantially more likely to be black, and less likely to be from isolated rural areas.

Veterans in the criminal justice, homeless and vocational program groups were all less likely to have a service-connected disability rating of $50 \%$ or more than those seen in clinics. There were few differences on the Charlson index of medical co-morbidity although those in vocational program group had a lower index of medical problems than those seen in clinics, and veterans treated in each of the four community program groups had greater risks of HIV and hepatic diagnoses.

Most dramatic were the substantially 2-3 times greater numbers with any drug or alcohol abuse or dependence diagnoses in all four community-based program groups as compared to the clinic group, with Cohen's $d$ 's of greater than 0.5 for the total number of such diagnoses and risk ratios for each specific drug and alcohol use diagnosis greater than 2.0 (Table 2).

Numbers of non-substance use psychiatric diagnoses were substantially greater in the SMI program group with Cohen's $d$ of .69 and fewer in the criminal justice programs with Cohen's $d$ of -.29 . Individual diagnoses most strongly associated with the SMI programs included schizophrenia, and bipolar disorder. While proportions of veterans diagnosed with personality disorder were greater in all four community program groups than in outpatient clinics, they were 4 times more common in the SMI programs even though personality disorder is not considered a serious mental illness (Table 2).

Veterans in each of the four community program groups had far more psychiatric and substance use outpatient visits than those seen in outpatient mental health clinics (Table 3), and participants in the SMI and vocational programs had more general psychiatry visits over and above the visits to specialized community service programs themselves, and three times as many total mental health outpatient contacts (totaling 51.63/year) overall. Veterans in all community program groups were more likely to have been hospitalized for psychiatric treatment compared to those seen in mental health clinics alone. There were no substantial differences in primary care or medical specialty visits although veterans seen in the criminal justice and SMI programs were more likely to have had medical hospitalizations (Table 3).

Veterans served by the SMI program group also had three times as many psychotropic prescription fills as those only seen in outpatient clinics, but substantial differences in psychotropic prescription fills were not seen in association with other community-based programs. Veterans who received SMI services filled far more 


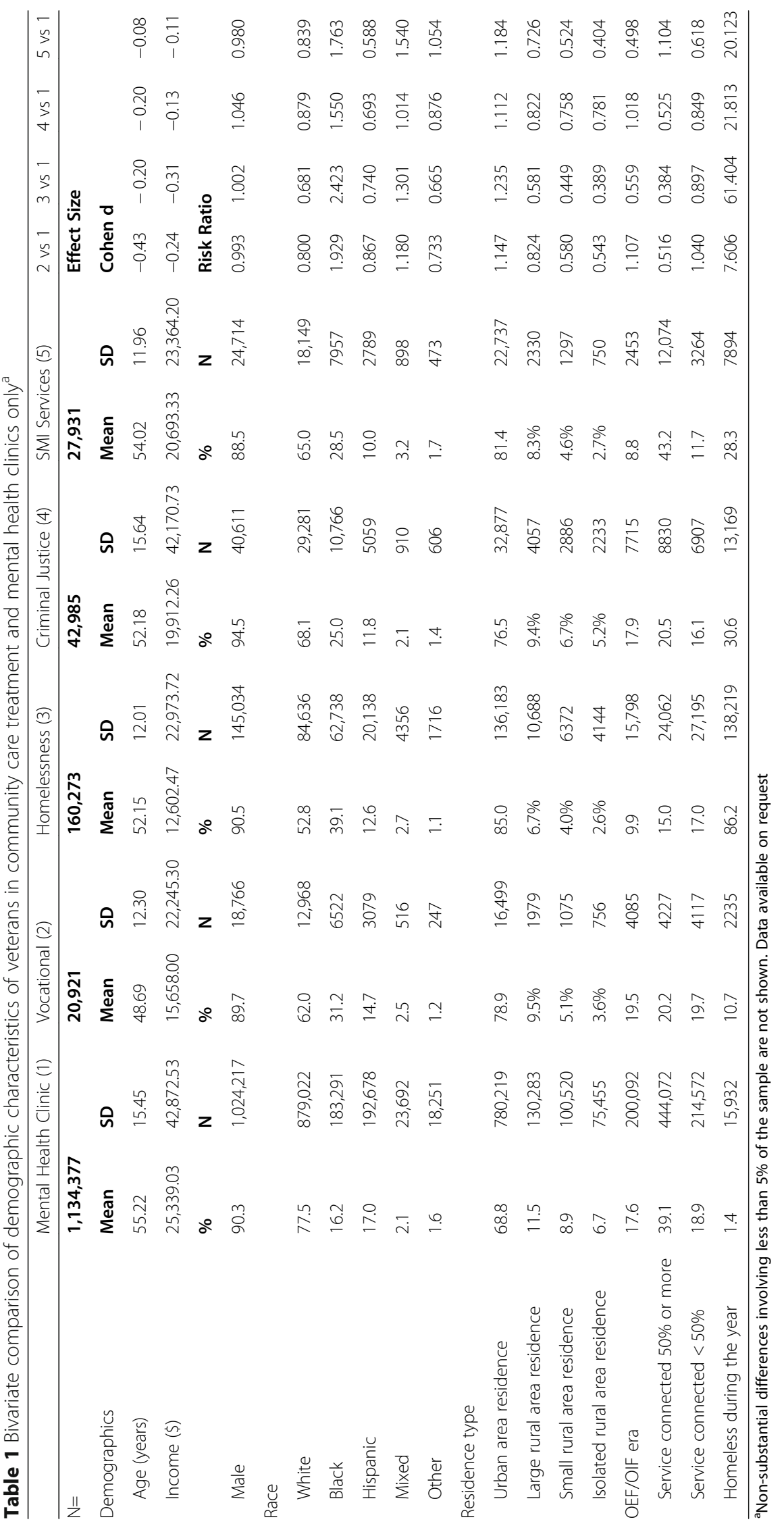




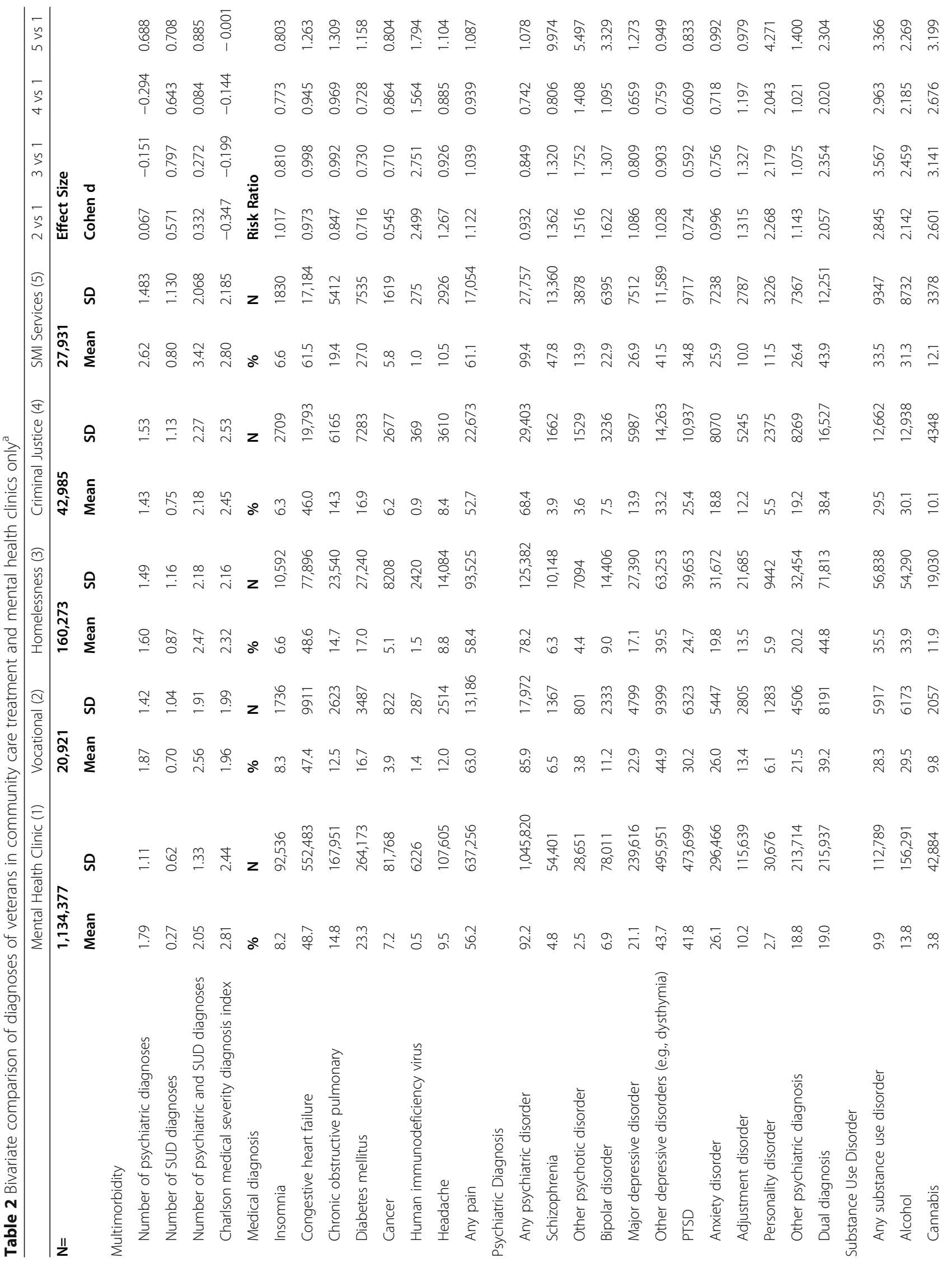




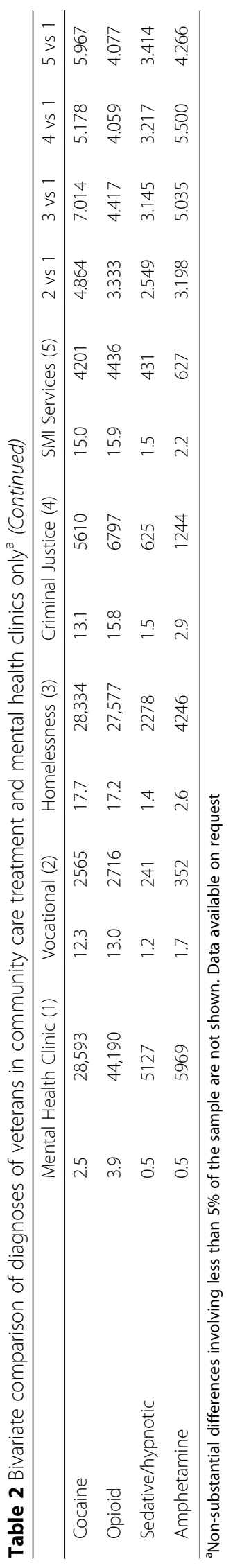


Table 3 Bivariate comparison of service utilization and psychotropic prescription fills among veterans in community care treatment and mental health clinics only

\begin{tabular}{|c|c|c|c|c|c|c|c|c|c|c|c|c|c|c|}
\hline \multirow{3}{*}{$\mathrm{N}=$} & \multicolumn{2}{|c|}{$\begin{array}{l}\text { Mental Health } \\
\text { Clinic (1) }\end{array}$} & \multicolumn{2}{|c|}{$\begin{array}{l}\text { Vocational } \\
\text { (2) }\end{array}$} & \multicolumn{2}{|c|}{$\begin{array}{l}\text { Homelessness } \\
\text { (3) }\end{array}$} & \multicolumn{2}{|c|}{$\begin{array}{l}\text { Criminal } \\
\text { Justice (4) }\end{array}$} & \multicolumn{2}{|c|}{$\begin{array}{l}\text { SMl Services } \\
\text { (5) }\end{array}$} & \multirow{2}{*}{\multicolumn{2}{|c|}{$\begin{array}{l}2 \text { vs } 13 \text { vs } 1 \\
\text { Effect Size }\end{array}$}} & \multirow[t]{2}{*}{4 vs 1} & \multirow[t]{2}{*}{5 vs 1} \\
\hline & $1,134,3$ & 377 & 20,921 & & 160,27 & & 42,985 & & 27,931 & & & & & \\
\hline & Mean & SD & Mean & SD & Mean & SD & Mean & SD & Mean & SD & Cohen & & & \\
\hline General psychiatry visits & 5.81 & 9.27 & 15.96 & 22.89 & 16.51 & 24.43 & 11.83 & 22.54 & 67.37 & 74.42 & 0.602 & 0.634 & 0.357 & 3.650 \\
\hline $\begin{array}{l}\text { General psychiatry visits excluding } \\
\text { community-based programs }\end{array}$ & 5.81 & 9.27 & 10.60 & 20.01 & 8.04 & 19.65 & 6.00 & 16.69 & 15.98 & 28.61 & 0.389 & 0.181 & 0.016 & 0.826 \\
\hline Substance abuse clinic visits & 0.90 & 7.91 & 7.76 & 25.47 & 8.08 & 26.01 & 8.31 & 24.94 & 7.17 & 25.34 & 0.515 & 0.539 & 0.556 & 0.471 \\
\hline Medical surgical visits & 9.60 & 11.12 & 10.66 & 11.40 & 10.07 & 11.76 & 9.54 & 12.27 & 13.45 & 14.53 & 0.092 & 0.040 & -0.006 & 0.334 \\
\hline Primary care visits & 3.43 & 3.50 & 4.02 & 3.86 & 3.93 & 4.24 & 3.27 & 3.96 & 4.71 & 5.08 & 0.156 & 0.134 & -0.044 & 0.344 \\
\hline Specialty medical clinic visits & 6.17 & 9.35 & 6.64 & 9.40 & 6.14 & 9.52 & 6.26 & 10.16 & 8.74 & 12.12 & 0.049 & -0.003 & 0.010 & 0.267 \\
\hline \multirow[t]{2}{*}{ Emergency room visits } & 0.60 & 1.58 & 1.06 & 2.32 & 1.37 & 2.97 & 1.22 & 2.67 & 1.87 & 4.13 & 0.232 & 0.388 & 0.313 & 0.644 \\
\hline & $\%$ & $\mathrm{~N}$ & $\%$ & $\mathbf{N}$ & $\%$ & $\mathbf{N}$ & $\%$ & $\mathbf{N}$ & $\%$ & $\mathbf{N}$ & \multicolumn{3}{|c|}{ Risk Ratio } & \\
\hline Any mental health inpatient treatment & 2.8 & $\begin{array}{l}32 \\
134\end{array}$ & 8.0 & 1674 & 10.3 & 16,581 & 9.4 & 4029 & 25.2 & 7037 & 2.825 & 3.652 & 3.309 & 8.894 \\
\hline $\begin{array}{l}\text { Any medical surgical inpatient } \\
\text { treatment }\end{array}$ & 7.9 & $\begin{array}{l}90, \\
143\end{array}$ & 8.7 & 1814 & 11.6 & 18,563 & 12.0 & 5154 & 14.3 & 4007 & 1.091 & 1.458 & 1.509 & 1.805 \\
\hline Psychotropic medication prescriptions & Mean & SD & Mean & SD & Mean & SD & Mean & SD & Mean & SD & \multicolumn{2}{|c|}{ Cohen d } & & \\
\hline Antidepressant prescriptions & 5.67 & 9.79 & 6.45 & 16.22 & 5.84 & 13.63 & 5.26 & 13.52 & 12.37 & 25.31 & 0.069 & 0.015 & -0.037 & 0.595 \\
\hline Antipsychotic prescriptions & 1.76 & 8.09 & 2.65 & 11.73 & 2.53 & 10.53 & 2.06 & 9.29 & 16.41 & 35.24 & 0.089 & 0.077 & 0.030 & 1.467 \\
\hline $\begin{array}{l}\text { Anxiolytic/sedative/hypnotic } \\
\text { prescriptions }\end{array}$ & 2.90 & 5.64 & 2.29 & 6.57 & 1.92 & 5.71 & 1.78 & 5.33 & 4.77 & 9.73 & -0.104 & -0.167 & -0.192 & 0.318 \\
\hline Stimulant prescriptions & 0.16 & 1.28 & 0.20 & 3.52 & 0.10 & 1.74 & 0.10 & 1.38 & 0.13 & 1.32 & 0.024 & -0.042 & -0.042 & -0.024 \\
\hline $\begin{array}{l}\text { Anticonvulsant/Mood Stabilizer } \\
\text { Prescriptions }\end{array}$ & 1.55 & 6.09 & 2.08 & 8.64 & 2.19 & 9.04 & 2.04 & 9.04 & 7.12 & 21.19 & 0.072 & 0.087 & 0.067 & 0.756 \\
\hline Lithium prescriptions & 0.13 & 1.65 & 0.25 & 2.51 & 0.21 & 2.51 & 0.18 & 2.18 & 1.47 & 9.95 & 0.052 & 0.033 & 0.022 & 0.577 \\
\hline All Psychotropics & 13.03 & 21.03 & 14.74 & 33.21 & 14.40 & 30.33 & 13.85 & 30.64 & 43.05 & 70.05 & 0.068 & 0.054 & 0.033 & 1.189 \\
\hline Opiate Prescriptions & 7.51 & 7.50 & 6.72 & 7.70 & 7.20 & 8.32 & 6.81 & 8.61 & 7.49 & 9.38 & -0.101 & -0.040 & -0.090 & -0.002 \\
\hline $\begin{array}{l}\text { Intensive community treatment } \\
\text { programs }\end{array}$ & Mean & SD & Mean & SD & Mean & SD & Mean & SD & Mean & SD & \multicolumn{2}{|c|}{ Cohen d } & & \\
\hline SMI Services & 0.00 & 0.00 & 0.00 & 0.00 & 0.00 & 0.00 & 0.00 & 0.00 & 46.58 & 67.38 & $\mathrm{n} / \mathrm{a}$ & $\mathrm{n} / \mathrm{a}$ & $\mathrm{n} / \mathrm{a}$ & $\mathrm{n} / \mathrm{a}$ \\
\hline $\begin{array}{l}\text { Criminal justice outreach, jail } \\
\text { diversion visits }\end{array}$ & 0.00 & 0.00 & 0.00 & 0.00 & 0.00 & 0.00 & 2.45 & 4.27 & 0.19 & 1.64 & $\mathrm{n} / \mathrm{a}$ & $\mathrm{n} / \mathrm{a}$ & $\mathrm{n} / \mathrm{a}$ & $\mathrm{n} / \mathrm{a}$ \\
\hline Homelessness visits & 0.00 & 0.00 & 0.00 & 0.00 & 7.49 & 10.95 & 2.70 & 8.45 & 3.30 & 10.08 & $\mathrm{n} / \mathrm{a}$ & $\mathrm{n} / \mathrm{a}$ & $\mathrm{n} / \mathrm{a}$ & $\mathrm{n} / \mathrm{a}$ \\
\hline Vocational rehabilitation visits & 0.00 & 0.00 & 5.36 & 9.63 & 1.54 & 5.93 & 1.03 & 5.05 & 1.56 & 6.08 & $\mathrm{n} / \mathrm{a}$ & $\mathrm{n} / \mathrm{a}$ & $\mathrm{n} / \mathrm{a}$ & $\mathrm{n} / \mathrm{a}$ \\
\hline $\begin{array}{l}\text { Total intensive community treatment } \\
\text { visits }\end{array}$ & 0.00 & 0.00 & 5.36 & 9.63 & 9.04 & 13.41 & 6.18 & 12.46 & 51.63 & 68.38 & $\mathrm{n} / \mathrm{a}$ & $\mathrm{n} / \mathrm{a}$ & $\mathrm{n} / \mathrm{a}$ & $\mathrm{n} / \mathrm{a}$ \\
\hline
\end{tabular}

antipsychotic prescriptions. There were no substantial differences in numbers of prescriptions for opiates (Table 3).

Multinomial logistic regression showed that, independent of other factors, veterans in the homeless and vocational program groups had lower incomes and were less likely to have a service-connected disability status of greater than $50 \%$ than those in the mental health clinic group. Veterans serviced by criminal justice programs had a lower total number of non-substance use psychiatric diagnoses (psychiatric multi-morbidity) whereas those in SMI programs had a substantially higher number of such diagnoses. Perhaps the most dramatic independent association was that Veterans in each of the four community program groups were diagnosed with more numerous substance use disorders than those in the clinic group (Table 4).

\section{Discussion}

This study used national VHA data to compare the proportions and characteristics of the $82 \%$ of veterans treated exclusively in traditional mental health outpatient clinics 
Table 4 Multinomial logistic regression with multimorbidity characteristics, comparing veterans treated in community psychiatry care with those in mental health

\begin{tabular}{|c|c|c|c|c|c|c|c|c|}
\hline & \multicolumn{2}{|c|}{ Vocational } & \multicolumn{2}{|c|}{ Homeless } & \multicolumn{2}{|c|}{ Criminal Justice } & \multicolumn{2}{|c|}{$\underline{\text { SMI Services }}$} \\
\hline & OR & $\begin{array}{l}\text { Standardized } \\
\text { Regression } \\
\text { coefficient }\end{array}$ & $\overline{\mathrm{OR}}$ & $\begin{array}{l}\text { Standardized } \\
\text { Regression } \\
\text { coefficient }\end{array}$ & $\overline{O R}$ & $\begin{array}{l}\text { Standardized } \\
\text { Regression } \\
\text { coefficient }\end{array}$ & $\mathrm{OR}$ & $\begin{array}{l}\text { Standardized } \\
\text { Regression } \\
\text { coefficient }\end{array}$ \\
\hline \multicolumn{9}{|l|}{ Demographics } \\
\hline Age & 0.977 & $-0.191^{* *}$ & 0.993 & $-0.0574^{* *}$ & 0.991 & $-0.075^{* *}$ & 1.002 & $0.015^{* *}$ \\
\hline Income & 1.000 & $-0.200^{* *}$ & 1.000 & $-0.413^{* *}$ & 1.000 & $-0.040^{* *}$ & 1.000 & $-0.062^{* *}$ \\
\hline Black race & 2.040 & $0.156^{* *}$ & 2.570 & $0.206^{* *}$ & 1.422 & $0.077^{* *}$ & 1.799 & $0.128^{* *}$ \\
\hline Small rural area residence & 0.638 & $-0.068^{* *}$ & 0.509 & $-0.102^{* *}$ & 0.836 & $-0.027^{* *}$ & 0.513 & $-0.100^{* *}$ \\
\hline Isolated rural area residence & 0.635 & $-0.059^{* *}$ & 0.478 & $-0.097^{* *}$ & 0.896 & $-0.015^{* *}$ & 0.406 & $-0.118^{* *}$ \\
\hline Pension & 1.142 & $0.014^{*}$ & 1.614 & $0.050^{* *}$ & 1.018 & $0.002^{* *}$ & 2.480 & $0.095^{* *}$ \\
\hline Service connected $50 \%$ or more & 0.466 & $-0.202^{* *}$ & 0.394 & $-0.246^{* *}$ & 0.493 & $-0.187^{* *}$ & 1.279 & $0.065^{* *}$ \\
\hline \multicolumn{9}{|l|}{ Diagnoses } \\
\hline Connective tissue disease & 0.822 & -0.011 & 0.772 & $-0.014^{* *}$ & 1.018 & $0.001^{* *}$ & 0.643 & $-0.024^{* *}$ \\
\hline Hepatic disease & 1.207 & $0.021 * *$ & 1.255 & $0.025^{* *}$ & 1.014 & $0.002^{* *}$ & 1.070 & 0.0070 \\
\hline Human immunodeficiency virus & 1.480 & $0.018^{* *}$ & 1.268 & $0.011^{* *}$ & 1.011 & $0.001^{* *}$ & 1.075 & 0.0030 \\
\hline Dementia & 0.233 & $-0.094^{* *}$ & 0.304 & $-0.077^{* *}$ & 0.868 & $-0.009^{* *}$ & 0.709 & $-0.022^{* *}$ \\
\hline \multicolumn{9}{|l|}{ Multi-morbidity } \\
\hline Number of psychiatric diagnoses & 1.004 & 0.003 & 0.840 & $-0.115^{* *}$ & 0.714 & $-0.222^{* *}$ & 1.482 & $0.260^{* *}$ \\
\hline $\begin{array}{l}\text { Number of substance use } \\
\text { disorder diagnoses }\end{array}$ & 1.666 & $0.217^{* *}$ & 1.953 & $0.285^{* *}$ & 2.025 & $0.300^{* *}$ & 1.663 & $0.217^{* *}$ \\
\hline \multicolumn{9}{|l|}{ Service Use } \\
\hline $\begin{array}{l}\text { General psychiatry visits } \\
\text { excluding community-based } \\
\text { programs }\end{array}$ & 1.019 & $0.130^{* *}$ & 1.015 & $0.106^{* *}$ & 1.009 & $0.062^{* *}$ & 1.018 & $0.126^{* *}$ \\
\hline Substance abuse clinic visits & 1.018 & $0.132^{* *}$ & 1.016 & $0.118^{* *}$ & 1.019 & $0.141^{* *}$ & 1.013 & $0.097^{* *}$ \\
\hline Medical surgical clinic visits & 1.012 & $0.076^{* *}$ & 1.006 & $0.036^{* *}$ & 1.008 & $0.048^{* *}$ & 1.007 & $0.047^{* *}$ \\
\hline Emergency room visits & 1.065 & $0.070^{* *}$ & 1.105 & $0.111 * *$ & 1.107 & $0.113^{* *}$ & 1.073 & $0.078^{* *}$ \\
\hline $\begin{array}{l}\text { Any mental health inpatient } \\
\text { treatment }\end{array}$ & 1.446 & $0.043^{* *}$ & 2.138 & $0.089^{* *}$ & 2.516 & $0.108^{* *}$ & 3.267 & $0.139^{* *}$ \\
\hline $\begin{array}{l}\text { Any medical surgical inpatient } \\
\text { treatment }\end{array}$ & 0.850 & $-0.026^{* *}$ & 1.081 & $0.013^{* *}$ & 1.270 & $0.038^{* *}$ & 0.899 & $-0.017^{* *}$ \\
\hline All psychotropic medications & 1.001 & $0.017^{*}$ & 1.000 & -0.004 & 0.998 & $-0.033^{* *}$ & 1.007 & $0.100^{* *}$ \\
\hline
\end{tabular}

to the $18 \%$ of veterans treated in VHA's four major specialized community-based programs. Veterans treated in all four types of community programs were distinguished most strikingly, by being diagnosed with $2-3$ times more numerous multimorbid substance use disorders, were more likely to have HIV and hepatic disease, to be from urban areas, of black race and also, as expected, had 3-13 times more mental health outpatient visits, most of which were in community-based programs themselves. Veterans served in the specialized programs for SMI veterans (only $2 \%$ of the total) were much more likely than clinic patients to be diagnosed with psychotic disorders, to manifest psychiatric multimorbidity and personality disorders and had 13 times more total visits, receiving over three times as many prescriptions for psychotropic medications.
In the decades after the closure of public psychiatric hospitals in the 1950s-70s, public mental health systems faced the question of how to address the broad needs of: 1) SMI patients who formerly would have been institutionalized, as well as the needs of emerging populations of 2) homeless people with mental illnesses; 3) criminal justice involved adults with mental health disorders; 4) veterans seeking rehabilitation/employment along with 5) a much larger group of people newly seeking effective care for less severe problems. The intensive community programs included in this study all originated in a push by VHA to develop care beyond the clinic in the community, primarily to better address the clinical challenges of SMI. At their inception, these programs were at times organizationally integrated [55] or co-located 
[56] together and with primary care services. While there has been extensive documentation of the reduction in long term State and VHA psychiatric hospital beds [5, $54,55]$, and many studies of the growth of outpatient mental health treatment generally [56-58]; we know of no previous system-wide studies of the place of community-based services in any public mental health system nor of characteristics of people who use these services as compared to people served by standard outpatient clinics.

On the one hand, available studies have examined mental health service delivery in the US as a whole and have shown that "the system" faces major challenges with respect to the treatment engagement of people with serious mentally illness [57]. On the other, the National Comorbidity Survey (NCS) and NCS Replication show that between 1990 and 2003 basic treatment rates for people with mental illness increased significantly while the overall rates of mental illness did not change [58] although many remained underserved [59]. Additionally, among people with SMI, rates of any mental health treatment increased from 24.3 to $40.5 \%$ [58]. Furthermore, data from the Healthcare for Communities Survey showed an increase in mental health specialty treatment for people with SMI from 39\% in 1997 to 51\% in 2001 with an even larger increase (from 47 to $76 \%$ ) for the subgroup who perceived a need for treatment [60]. These studies, however, did not examine communitybased services, specifically, and most studies have focused on people with mild to moderate mental illness. For example, studies of the National Ambulatory Medical Care Survey found that treatment for depression tripled between 1987 and 1997 [61], and that most antidepressants are prescribed by primary care providers $[62,63]$.

Local studies based on Medicaid data do show that community programs continued to provide ACT and ACT-like services to the most seriously mentally ill and functionally impaired adults [64], though one recent survey suggested that less than $20 \%$ of non-VA community mental health facilities offer ACT [65] and even fewer offer other community services such as peer support, employment, and housing services [66]. While most research has focused on either people who use less intensive services (i.e. from standard mental health outpatient clinics) or specific community-based treatments like ACT or supported housing, no study to our knowledge has addressed the broad array of clinic and intensive community-based services offered together in a national system or even in one community. The present study, based on VHA data showed intensive community-based service are provided to $18 \%$ of those receiving any specialty mental health services especially to those with multiple substance use disorders, severe mental illness, criminal justice involvement, and/or homelessness. A previous study of VHA care showed that considering all patients with psychiatric diagnoses, one-third receive no specialty mental health treatment at all and receive care for mental disorders exclusively in primary or specialty care clinic settings [67]. That study and this one taken together, thus appear to be unique in mapping the major components of VHA mental health care, a comprehensive mental health system in which most patients receive care in standard outpatient mental health and primary care clinics but distinct subgroups receive intensive community-focused care largely shaped by social determinants and SUD-related multimorbidity.

In view of this perspective, it is notable that several recent reviews have emphasized the unique role of mental health services in addressing social determinants of health as well as individual biomedical conditions [26, $27,68]$. The portrait of community-based care in VHA presented here illustrates the way mental health systems have been shaped by a few major social determinants of health, an approach that differs from the more comprehensive approach taken by others $[47,48]$. As clinicians, Sheilds-Zeeman described two types of intervention which are referred to as "social risk-informed" care and "social risk-targeted care." Social risk-informed care tailors clinical plans to reduce the effect of social or economic adversity, most often in conventional clinic settings, without necessarily targeting the social condition itself. Social risk-targeted care, in contrast, more directly helps patients to reduce social or economic adversity, and is more focused on community intervention. The community-based programs described here fall into both categories in that they seek to provide in vivo services at the individual level focusing on real world adaptation to challenging circumstances while also directly addressing patient-level problems such as housing, criminal justice involvement, impaired activities of daily living, limited employment opportunities, social isolation and a stigmatizing environment. The developing conceptualization of mental health care within a social determinants of health framework, thus provides an overarching context for understanding the unique role of community-focused programs.

Several methodological limitations of this study require comment. First, our ability to identify services delivered through community-based programs is limited to those identified by specific clinic codes in VHA administrative records. It is likely that other programs in VHA that would conform to our concept of community-based care that were implemented through local initiatives, which we could not identify. However, those examined here were developed through national initiatives, often supported by special funding and are probably the largest and best defined. 
Second, perhaps the social determinant of health least considered by this study is poverty. The need for income supports is addressed by VA through specific disability compensation and pension programs which provide income benefits for many veterans and which and have been shown to substantially reduce the risk of homelessness [69]. These programs were found, in this study, to be less commonly used by veterans served by outreach to criminal justice involved and by homeless veterans although their access to these benefits has been shown to increase after, and most likely as a result of, participation in VHA's community-based programs [70]. Crucial data are also not generally available in VA administrative records on the income obtained from social security and local welfare programs. However. specific outreach efforts to facilitate access to social security benefits have been successfully undertaken by VHA in collaboration with the Social Security Administration [71, 72].

Third, the definition of intensive community-based programs is not precise and while most programs addressed here involve frequent contact with veterans outside of health care facilities there is variability from program to program (e.g. criminal justice programs focus on linkage rather than intensive service delivery) and facility to facility in the extent of vivo as contrasted with office-based service delivery in these programs. Nevertheless, all of the programs are intended to address exceptionally serious clinical conditions and specific socially determined challenges to community adaptation.

Fourth, this study focuses on data from the VHA which offers the advantage of providing comprehensive national data from electronic health records. However, VHA is federally funded and operated and serves only veterans, who are overwhelmingly male, and thus its generalizability to other populations and health systems is unknown. The extent to which veterans studied here received non-VA services is also unknown. This study offers a sketch of one system which, it is hoped, will stimulate similar studies of others.

Finally, the data used in this study are somewhat dated as they are now 8 years old. However, 2012 was closer than more contemporary data to the point in time when community-based services emerged in the VHA in response to emerging social needs of several subgroups of veterans. In addition, a recent study [31] found little change in the characteristics of homeless veterans treated by VHA from FY 2008 to FY 2015, a major segment of the population with social challenges that the VHA now serves through communitybased programs.

This study could not describe each type of intensive community-based program offered by the VHA in detail but rather, summarized their primary service models and characterize the veterans they serve. We do provide data on the average number of contacts of each program with the veterans it serves.

\section{Conclusion}

In 2012, almost one-fifth of VHA mental health patients received specialized community-based services addressing, most distinctively, major social determinants of health and multimorbid substance use disorders. While the effectiveness, and cost-effectiveness of these individual services has been demonstrated in randomized trials $[25,39,73,74]$, evaluation of the accessibility and effectiveness of such programs in the context of large regional and national service systems is a far more challenging task, and remains to be undertaken.

\section{Abbreviations}

ACT: Assertive community treatment; FY: Fiscal year; HIV: Human immunodeficiency virus; ICD: International Classification of Diseases; NCS: National Comorbidity Survey; SMI: Severe mental illness; VA: Veterans Affairs; VHA: Veterans Health Administration

\section{Acknowledgements}

We have no acknowledgements.

\section{Authors' contributions}

RR and IB designed the study, and wrote and edited the manuscript. ES completed the data analysis. All authors contributed to and have approved the final manuscript.

\section{Funding}

This work was funded by the U.S. Department of Veterans Affairs.

\section{Availability of data and materials}

The data that support the findings of this study are available from the Veterans Health Administration but restrictions apply to the availability of these data, which were used under license for the current study, and so are not publicly available. Data are however available from the authors upon reasonable request and with permission of the Veterans Health

Administration.

\section{Ethics approval and consent to participate}

The study was approved by the Institutional Review Board committee of the VA Connecticut Healthcare System. A waiver of informed consent was obtained as the study used administrative data and there were no patient identifiers included.

\section{Consent for publication}

Not applicable.

\section{Competing interests}

On behalf of all authors, the corresponding author states that there is no conflict of interest.

\section{Author details \\ ${ }^{1}$ Yale University Department of Psychiatry, 950 Campbell Ave, Building 35, West Haven, CT 06516, USA. ² University of California, Los Angeles National Clinician Scholars Program, 1100 Glendon Ave, Suite 900, Los Angeles, CA 90024, USA. ${ }^{3}$ Veterans Affairs New England Mental Illness Research Education, and Clinical Center, West Haven, USA. ${ }^{4}$ Yale University School of Public Health, 950 Campbell Ave, Building 35, West Haven, CT 06516, USA.}

Received: 8 April 2020 Accepted: 18 August 2020

Published online: 28 August 2020

\section{References}

1. Talbott JA. Unified mental health systems: utopia unrealized. Vol 18. San Francisco: Jossey-Bass Inc Pub; 1983. 
2. Regier DA, Narrow WE, Rae DS, Manderscheid RW, Locke BZ, Goodwin FK. The de facto US mental and addictive disorders service system: epidemiologic catchment area prospective 1-year prevalence rates of disorders and services. Arch Gen Psychiatry. 1993;50(2):85-94.

3. Brown P. The transfer of care: psychiatric deinstitutionalization and its aftermath; 1985.

4. Torrey EF. Nowhere to go: the tragic odyssey of the homeless mentally ill; 1988.

5. Lutterman T, Shaw R, Fisher W, Manderscheid R. Trend in psychiatric inpatient capacity, United States and each state, 1970 to 2014. Alexandria: National Association of State Mental Health Program Directors; 2017.

6. Deutsch A. The shame of the states. 1st ed. New York: Harcourt; 1948.

7. Lamb HR. Deinstitutionalization and the homeless mentally ill. Psychiatr Serv. 1984;35(9):899-907.

8. Zusman J, Lamb HR. In defense of community mental health. Am J Psychiatry. 1977;134(8):887-90. https://doi.org/10.1176/ajp.134.8.887.

9. Stein LI, Test MA. Alternative to mental hospital treatment: I. conceptual model, treatment program, and clinical evaluation. Arch Gen Psychiatry. 1980;37(4):392-7.

10. Braun P, Kochansky G, Shapiro R, Greenberg S, Gudeman JE, Johnson S, et al. Overview: deinstitutionalization of psychiatric patients, a critical review of outcome studies. Am J Psychiatry. 1981;138(6):736-49.

11. Weisbrod BA, Test MA, Stein LI. Alternative to mental hospital treatment: II. Economic benefit-cost analysis. Arch Gen Psychiatry. 1980;37(4):400-5.

12. Mosher LR. Alternatives to psychiatric hospitalization. Why has research failed to be translated into practice? N Engl J Med. 1983;309(25):1579-80. https://doi.org/10.1056/NEJM198312223092512.

13. Turner JC, TenHoor WJ. The NIMH Community support program: pilot approach to a needed social reform. Schizophr Bull. 1978;4(3):319.

14. Becker DR, Drake RE. Individual placement and support: a community mental health center approach to vocational rehabilitation. Community Ment Health J. 1994;30(2):193-206.

15. Anthony WA, Cohen MR, Farkas MD. Psychiatric rehabilitation. Boston: Center for Psychiatric Rehabilitation, Boston University, Sargent College of Allied Health Professions; 1990

16. Bond GR, Becker DR, Drake RE, Rapp CA, Meisler N, Lehman AF, et al. Implementing supported employmentas an evidence-based practice. Psychiatr Serv. 2001;52(3):313-22.

17. Bond GR, Drake RE. Making the case for IPS supported employment. Adm Policy Ment Health Ment Health Serv Res. 2014;41(1):69-73.

18. Bassuk EL, Lamb HR. Homelessness and the implementation of deinstitutionalization. New Dir Ment Health Serv. 1986;1986(30):7-14

19. Scallet LJ. "Mental Health And Homelessness: Evidence Of Failed Policy?." Health Affairs. 1989;8(4)184-8.

20. Burt MM. Over the edge: the growth of homelessness in the 1980s. New York: Russell Sage Foundation; 1992

21. Pepper B, Kirshner MC, Ryglewicz H. The young adult chronic patient: overview of a population. Psychiatr Serv. 1981;32(7):463-9.

22. Teplin LA. The prevalence of severe mental disorder among male urban jail detainees: comparison with the epidemiologic catchment area program. Am J Public Health. 1990;80(6):663-9.

23. Junginger J, Claypoole K, Laygo R, Crisanti A. Effects of serious mental illness and substance abuse on criminal offenses. Psychiatr Serv. 2006;57(6):879-82.

24. Fazel S, Danesh J. Serious mental disorder in 23000 prisoners: a systematic review of 62 surveys. Lancet. 2002;359(9306):545-50. https://doi.org/10.1016/ S0140-6736(02)07740-1.

25. Sirotich $\mathrm{F}$. The criminal justice outcomes of jail diversion programs for persons with mental illness: a review of the evidence. J Amer Acad Psychiatry Law Online. 2009;37(4):461-72.

26. Hansen H, Braslow J, Rohrbaugh RM. From cultural to structural competency - training psychiatry residents to act on social determinants of health and institutional racism. JAMA Psychiat. 2018;75(2):117-8.

27. Shields-Zeeman L, Lewis C, Gottlieb L. Social and mental health care integration: the leading edge. JAMA Psychiat. 2019;76(9):881-2.

28. Compton MT, Shim RS. The social determinants of mental health. Focus. 2015;13(4):419-25.

29. Braslow JT, Messac L. Medicalization and Demedicalization-a gravely disabled homeless man with psychiatric illness. N Engl J Med. 2018;379(20):1885-8.

30. Roberts LW, Warner CH. Military and veteran mental health: a comprehensive guide. New York: Springer; 2018.
31. Rosenheck R, Sorkin H, Stefanovics E. Increasing the numbers of homeless veterans served by the veterans health administration from 2008 to 2015: maintaining focus on the intended target population and on sustaining service intensity. J Soc Distress Homeless. 2020:1-11. https://www. tandfonline.com/doi/full/10.1080/10530789.2020.1753914.

32. Rosenheck RA, Neale MS. Cost-effectiveness of intensive psychiatric community care for high users of inpatient services. Arch Gen Psychiatry. 1998:55(5):459-66.

33. VA Illiana Health Care System D, Illinois Mental Health Intensive Case Management Program (MHICM). https://www.danville.va.gov/services/ Mental_Health_Intensive_Case_Management_Program_MHICM.asp. Accessed 7 Apr 2019.

34. Affairs USDoV. Psychosocial rehabilitation and recovery center (PRRC); 2009. https://www.washingtondc.va.gov/departments/psychology-prrc.asp. Accessed 7 Apr 2019.

35. Tsai J, Rosenheck RA, J. Kasprow W, McGuire JF. Risk of incarceration and other characteristics of Iraq and Afghanistan era veterans in state and federal prisons. Psychiatr Serv. 2013;64(1):36-43.

36. Affairs USDoV. Veterans justice outreach program; 2019. https://www.va. gov/homeless/vjo.asp. Accessed 11 Apr 2019.

37. Finlay AK, Smelson D, Sawh L, McGuire J, Rosenthal J, Blue-Howells J, et al. US Department of veterans affairs veterans justice outreach program: connecting justice-involved veterans with mental health and substance use disorder treatment. Crim Justice Policy Rev. 2016;27(2):203-22.

38. Finlay AK, Stimmel M, Blue-Howells J, Rosenthal J, McGuire J, Binswanger I, et al. Use of veterans health administration mental health and substance use disorder treatment after exiting prison: the health Care for Reentry Veterans program. Adm Policy Ment Health Ment Health Serv Res. 2017; 44(2):177-87.

39. Rosenheck R, Kasprow W, Frisman L, Liu-Mares W. Cost-effectiveness of supported housing for homeless persons with mental illness. Arch Gen Psychiatry. 2003;60(9):940-51.

40. Tsai J. Homelessness among US veterans: a critical approach. USA: Oxford University Press; 2018.

41. Tsai J, Kasprow WJ, Rosenheck RA. Latent homeless risk profiles of a nationa sample of homeless veterans and their relation to program referral and admission patterns. Am J Public Health. 2013;103(S2):S239-47.

42. Affairs USDoV. Homeless veterans; 2019. https://www.va.gov/homeless/for homeless_veterans.asp. Accessed 11 Apr 2019.

43. Montgomery AE, Hill LL, Kane V, Culhane DP. Housing chronically homeless veterans: evaluating the efficacy of a housing first approach to HUD-VASH. J Community Psychol. 2013;41(4):505-14.

44. US Department of Veterans Affairs. Compensated work therapy; 2019. https://www.va.gov/health/cwt/. Accessed 11 Apr 2019.

45. Resnick SG, Rosenheck R. Dissemination of supported employment in Department of Veterans Affairs. J Rehabil Res Dev. 2007;44(6):867.

46. Resnick SG, Rosenheck RA. Posttraumatic stress disorder and employment in veterans participating in veterans health administration compensated work therapy. J Rehabil Res Dev. 2008;45(3):427-36.

47. Institute of Medicine. Capturing social and behavioral domains and measures in electronic health records: phase 2. Washington, DC: National Academies Press; 2015

48. Rhee TG, Marottoli RA, Cooney LM Jr, Fortinsky RH. Associations of social and behavioral determinants of health index with self-rated health, functional limitations, and health services use in older adults. J Am Geriatr Soc. 2020;68:1731-38.

49. North CS, Brown ES, Pollio DE. Expanded conceptualization of multimorbidity to encompass substance use disorders and other psychiatric illness. Ann Clin Psychiatry. 2016;28(3):182-8.

50. Bhalla IP, Rosenheck RA. A change in perspective: from dual diagnosis to multimorbidity. Psychiatr Serv. 2018;69(1):112-6. https://doi.org/10.1176/ appi.ps.201700194

51. Morrill R, Cromartie J, Hart G. Metropolitan, urban, and rural commuting areas: toward a better depiction of the United States settlement system. Urban Geogr. 1999;20(8):727-48.

52. Charlson ME, Pompei $P$, Ales $K L$, Mackenzie CR. A new method of classifying prognostic comorbidity in longitudinal studies: development and validation. J Chronic Dis. 1987:40(5):373-83.

53. Barry DT, Sofuoglu M, Kerns RD, Wiechers IR, Rosenheck RA. Prevalence and correlates of co-prescribing psychotropic medications with long-term 
opioid use nationally in the veterans health administration. Psychiatry Res. 2015;227(2-3):324-32.

54. Cohen J. Statistical power analysis for the behavioral sciences. 2nd ed. Hillsdale: Erlbaum Associates; 1988.

55. Berman S, Barilich JE, Rosenheck R, Koerber G. The VA's first comprehensive homeless center: a catalyst for public and private partnerships. Psychiatr Serv. 1993;44(12):1183-4.

56. Blue-Howells J, McGuire J, Nakashima J. Co-location of health care services for homeless veterans: a case study of innovation in program implementation. Soc Work Health Care. 2008;47(3):219-31.

57. Appelbaum PS. The 'quiet'crisis in mental health services. Health Aff. 2003; 22(5):110-6.

58. Kessler RC, Demler O, Frank RG, Olfson M, Pincus HA, Walters EE, et al. Prevalence and treatment of mental disorders, 1990 to 2003. N Engl J Med. 2005:352(24):2515-23.

59. Wang PS, Lane M, Olfson M, Pincus HA, Wells KB, Kessler RC. Twelve-month use of mental health services in the United States: results from the National Comorbidity Survey Replication. Arch Gen Psychiatry. 2005;62(6):629-40.

60. Mechanic D, Bilder S. Treatment of people with mental illness: a decadelong perspective. Health Aff. 2004;23(4):84-95.

61. Olfson M, Marcus SC, Druss B, Elinson L, Tanielian T, Pincus HA. National trends in the outpatient treatment of depression. Jama. 2002;287(2):203-9.

62. Mojtabai R, Olfson M. National patterns in antidepressant treatment by psychiatrists and general medical providers: results from the national comorbidity survey replication. J Clin Psychiatry. 2008;69(7):1064-74.

63. Rhee TG, Rosenheck RA. Initiation of new psychotropic prescriptions without a psychiatric diagnosis among US adults: rates, correlates, and national trends from 2006 to 2015. Health Serv Res. 2019;54(1):139-48,

64. Gilmer TP, Stefancic A, Ettner SL, Manning WG, Tsemberis S. Effect of fullservice partnerships on homelessness, use and costs of mental health services, and quality of life among adults with serious mental illness. Arch Gen Psychiatry. 2010;67(6):645-52.

65. Spivak S, Cullen BA, Green C, Firth T, Sater H, Mojtabai R. Availability of assertive community treatment in the United States: 2010 to 2016. Psychiatr Serv. 2019:appips201900032. https://doi.org/10.1176/appi.ps.201900032.

66. Spivak S, Mojtabai R, Green C, Firth T, Sater H, Cullen BA. Distribution and correlates of assertive community treatment (ACT) and ACT-like programs: results from the 2015 N-MHSS. Psychiatric services:appi ps. 2019;201700561: 271-8.

67. Gupta N, Bhalla IP, Rosenheck RA. Treatment of veterans with psychiatric diagnoses nationally in the veterans health administration: a comparison of service delivery by mental health specialists and other providers. Adm Policy Ment Health Ment Health Serv Res. 2019;46(3):380-90.

68. Shim RS, Compton MT. Addressing the social determinants of mental health: if not now, when? If not us, who? Psychiatr Serv. 2018;69(8):844-6.

69. Edens EL, Kasprow W, Tsai J, Rosenheck RA. Association of substance use and VA service-connected disability benefits with risk of homelessness among veterans. Am J Addict. 2011;20(5):412-9.

70. Chen JH, Rosenheck RA, Kasprow WJ, Greenberg G. Receipt of disability through an outreach program for homeless veterans. Mil Med. 2007;172(5): $461-5$.

71. Rosenheck RA, Dausey DJ, Frisman L, Kasprow W. Outcomes after initial receipt of social security benefits among homeless veterans with menta illness. Psychiatr Serv. 2000;51(12):1549-54.

72. Rosenheck R, Frisman L, Kasprow W. Improving access to disability benefits among homeless persons with mental illness: an agency-specific approach to services integration. Am J Public Health. 1999;89(4):524-8.

73. Phillips SD, Burns BJ, Edgar ER, Mueser KT, Linkins KW, Rosenheck RA, et al. Moving assertive community treatment into standard practice. Psychiatr Serv. 2001;52(6):771-9.

74. Frederick DE, VanderWeele TJ. Supported employment: meta-analysis and review of randomized controlled trials of individual placement and support. PLoS One. 2019;14(2):e0212208.

\section{Publisher's Note}

Springer Nature remains neutral with regard to jurisdictional claims in published maps and institutional affiliations.

\section{Ready to submit your research? Choose BMC and benefit from}

- fast, convenient online submission

- thorough peer review by experienced researchers in your field

- rapid publication on acceptance

- support for research data, including large and complex data types

- gold Open Access which fosters wider collaboration and increased citations

- maximum visibility for your research: over $100 \mathrm{M}$ website views per year

At BMC, research is always in progress.

Learn more biomedcentral.com/submissions 